\title{
Comparison of Femoral Torsion and Tibial Torsion in Spastic Diplegics and Spastic Quadriplegics
}

\author{
VenkataramaniAbhishek ${ }^{1}$, ThudukuchiRamanathanAshok ${ }^{2}$, GopinathaMenon ${ }^{3}$ \\ ${ }^{123}$ (Department of Orthopaedics, Sri Ramachandra University, Chennai-116, Tamilnadu, INDIA)
}

\begin{abstract}
: 95 children with cerebral palsy of varying age groups were examined clinically for their lower limb torsion. All the children come under two different types of cerebral palsy with spasticity. Femoral and tibial torsion were assessed individually, as they can alter the gait pattern in these children. In our study the femoral and tibial torsions were assessed clinically by assessing the femoral in-torsion and out-torsion, the trans malleolar axis and the thigh foot axis. These lower limb torsions vary within the two groups in this study, between limbs of the same individual and between different age groups. It is important to know the normal variations for better management and prognosis.
\end{abstract}

Keywords: Femoral in-torsion, out-torsion, Trans-malleolar axis, Thigh foot angle/axis.

\section{Introduction}

Torsional problems in children with cerebral palsy can produce abnormal gait patterns, if the child is able to walk, and sitting positions which are a major concern. These torsional abnormalities are usually masked in cerebral palsy children as they have other components of spasticity which can produce abnormalities of the lower limb. In this study, lower limb torsion of 95 children were assessed prospectively. All the children were spastic type of cerebral palsy with diplegia or quadriplegia. These torsional abnormalities are mostly benign and may resolve with growth. The treatment of such abnormalities are just observation and reassurance. No surgical intervention is required for such abnormalities as they correct themselves most the time.

\section{Aim}

To compare the femoral torsion and tibial torsion in children with cerebral palsy, between spastic diplegics and quadriplegics.

\section{Materials And Methods}

This is a prospective study done at Sri Ramachandra University, Chennai between August 2013 to August 2014. 95 cerebral palsy children were analysed in this study. The children were divided into two groups depending on the type of the disease, either diplegics or quadriplegics. All children varied from 3 to 15 years. Children who had other congenital abnormalities that would further affect the torsion of lower limbs, fractures limbs, pathologically affected limbs and if undergone any bony surgery to the lower limb, were not included in this study.

All the children were positioned prone and the following assessments were done which include:

1. Femoral in-torsion

2. Femoral out-torsion

3. Trans-malleolar axis

4. Thigh foot angle/axis

(The following clinical methods were adapted from Staheli LT: Torsional deformity, Pediatr Clin North Am $24: 799,1977$.

\section{Results}

All the cerebral palsy children were divided into two groups, diplegics and quadriplegics.

Figures And Tables:

Table 1. Number of children and type

\begin{tabular}{|l|l|l|l|}
\hline & Diplegics & Quadriplegics & Total \\
\hline Number & 36 & 59 & 95 \\
\hline
\end{tabular}

Table 2. Mean femoral in-torsion between each limb in both groups

\begin{tabular}{|l|l|l|}
\hline Femoral in-torsion & Diplegics & Quardiplegics \\
\hline Left & 65.97 & 66.86 \\
\hline Right & 66.94 & 67.12 \\
\hline
\end{tabular}


Table 3. Mean femoral out-torsion between each limb in both groups

\begin{tabular}{|l|l|l|}
\hline Femoral out-torsion & Diplegics & Quadriplegics \\
\hline Left & 61.22 & 58.22 \\
\hline Right & 60.81 & 60.25 \\
\hline
\end{tabular}

Table 4. Mean thigh foot angle between each limb in both groups

\begin{tabular}{|l|l|l|}
\hline Thigh foot angle & Diplegics & Quadriplegics \\
\hline Left & 13.63 & 9.60 \\
\hline Right & 14.70 & 9.70 \\
\hline
\end{tabular}

Table 5. Mean trans-malleolar axis between each limb in both groups

\begin{tabular}{|l|l|l|}
\hline Trans-malleolar axis & Diplegics & Quadriplegics \\
\hline Left & 16.41 & 16.49 \\
\hline Right & 18.03 & 17.02 \\
\hline
\end{tabular}

Table 6. Mean femoral torsion between diplegics and quadriplegics

\begin{tabular}{|l|l|l|}
\hline Mean femoral torsion & Diplegics & Quadriplegics \\
\hline Femoral in-torsion & 66.45 & 66.99 \\
\hline Femoral out-torsion & 61.01 & 59.23 \\
\hline
\end{tabular}

Table 7. Mean tibial torsion between diplegics and quadriplegics

\begin{tabular}{|l|l|l|}
\hline Mean tibial torsion & Diplegics & Quadriplegics \\
\hline Thigh foot angle & 14.16 & 9.65 \\
\hline Trans-malleolar axis & 17.22 & 16.75 \\
\hline
\end{tabular}

FIG 1. Mean femoral and tibial torsion between diplegics and quadriplegics

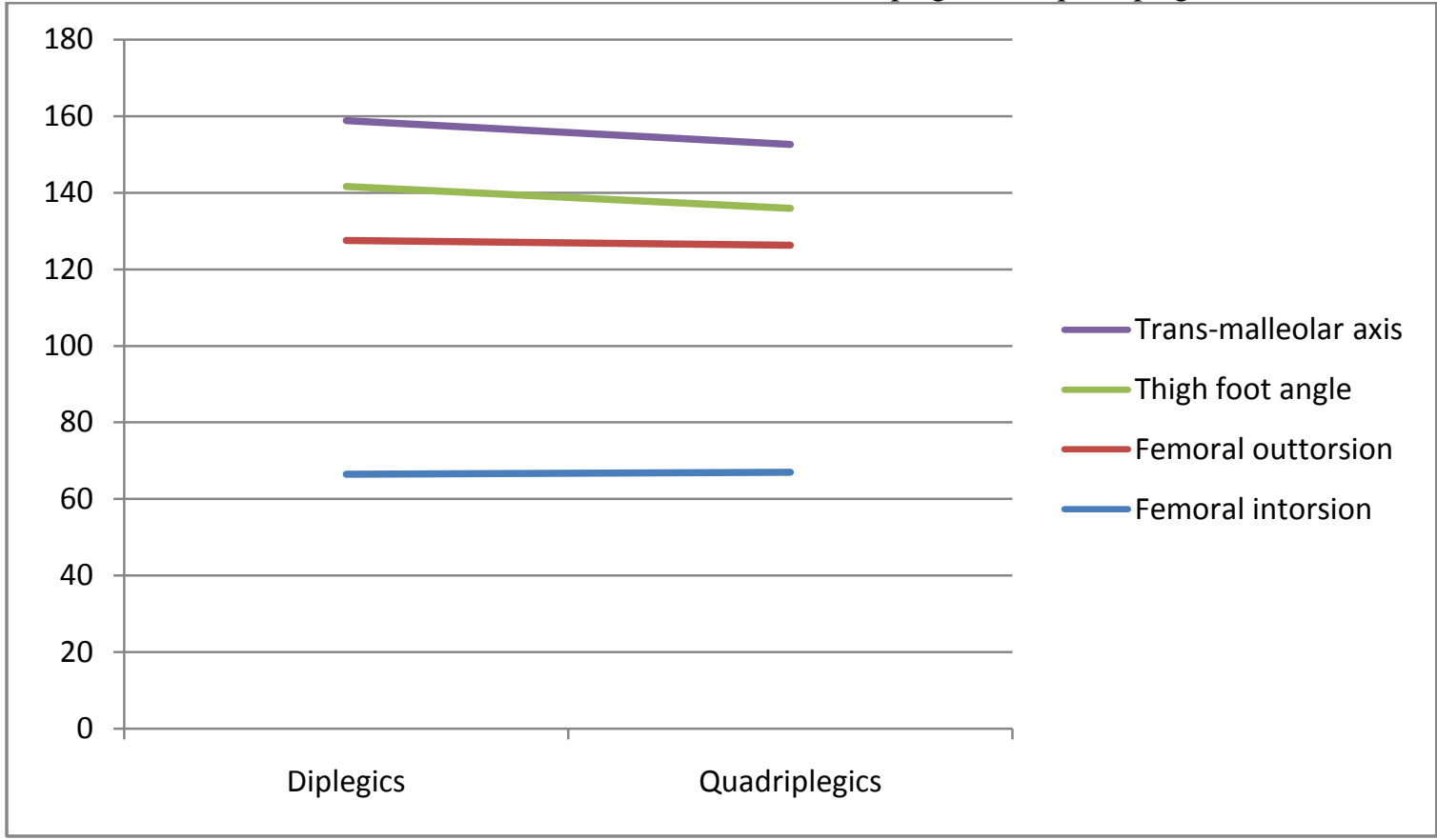

\section{Discussion}

In this study, 190 lower limbs were examined for their femoral and tibial torsions. All the limbs were examined individually with the child in prone using a simple goniometer. Foot progression angle was not evaluated in the study as many of the children were non walkers. None of the children in this study were affected with metatarsus adductus. It was noticed that, both spastic diplegics and quadriplegics have varying femoral and tibial torsion which vary with age and follow a patternof growth. The femoral torsion decreases with increase in age and tibial torsion increase with increase in age. Proper assessment of torsion is required, as they may be difficult to measure if spasticity is severe and the management varies depending on it. All the children can be left untreated until the growth spurt is over as the torsional variation may get corrected spontaneously with growth. Reassurance is the main line of management and none of these children require surgical intervention as they may resolve. 


\section{Conclusion}

1. Values need not have to be same on both the limbs of the same individual, they can alter within the normal range or more.

2. Femoral and tibial torsion follow a pattern of growth which should be known for appropriate management.

3. Femoral and tibial torsion between spastic diplegics and quadriplegics in not statistically significant in this study.

4. foot progression angle denotes the in-toeing and out-toeing gait, which reflects the femoral and tibial torsion.

\section{References}

[1]. Lee SH, Chung CY, In clinical orthopaedic relat res,2009 aug:467(8):2098-104

[2]. Staheli LT, In journal of family practice, 1983 may, 16(5):1005-11

[3]. Mooney JF $3^{\text {rd }}$, Paediatric clinical north America journal, 2014 december;61(06):1175-81

[4]. Gaumentou E, Quijano S, Llharreborere B, Presedo A, In Orthopaedic traumatology surgical res, 2014Feb;100(1):147-51

[5]. Blackmur JP, Murray AW, Journal of paediatric orthopaedics B, 2010 Sept;19(5):415-7

[6]. Lee KM, Chung CY, Sugh KH, Journal of neuroeng rehabilitation, 2013June

[7]. Rethlefsen SA, Healy BS, Wren TA, Journal of bone and joint surgery

[8]. Simon AL, Llharreborde, Bregrest F, mallet C, Journal of paediatric orthopaedics, 2015 Sept;31(6); 576-82

[9]. Carriero A, zovatsky A, Stebbins, Journal of paediatric orthopaedics 2009 Feb;29(1):73-79 